\title{
Synthesis of Needle-like BiVO4 with Improved Photocatalytic Activity under Visible Light Irradiation
}

\author{
Duy Trinh Nguyen and Seong-Soo Hong* \\ Department of Chemical Engineering, Pukyong National University, 365 Shinseonro, Busan, 48547, \\ Korea \\ *Corresponding author : sshong@pknu.ac.kr
}

\begin{abstract}
A highly crystallized monoclinic-scheelite type $\mathrm{BiVO}_{4}$ powders were successfully synthesized by solvothermal method. The as-synthesized $\mathrm{BiVO}_{4}$ powders were characterized by XRD, FE-SEM, Raman spectroscopy, UV-vis DRS spectroscopy and TA-PL. From the XRD data and Raman spectra, the monoclinic-scheelite phase $\mathrm{BiVO}_{4}$ sample can be obtained at higher solvothermal synthesis temperature more than $140{ }^{\circ} \mathrm{C}$. The preparation conditions such as, the $\mathrm{Bi} / \mathrm{V}$ molar ratio and synthesis temperature, have significantly effects on the morphologies of the $\mathrm{BiVO}_{4}$ samples. $\mathrm{BVO} 2$ sample shows the highest PL peak, which has the highest formation rate of $\mathrm{OH}$ radicals and the highest photocatalytic activity. This result suggests that the formation rate of $\mathrm{OH}$ radicals shows a good correlation with the photocatalytic activity.
\end{abstract}

Keywords: needle-like $\mathrm{BiVO}_{4}$, photodegradation of Rhodamine $\mathrm{B}$, monoclinic-scheelite type $\mathrm{BiVO}_{4}$ 


\section{Introduction}

Recently, bismuth based complex oxides such as $\mathrm{Bi}_{2} \mathrm{MoO}_{6}, \mathrm{BiFeO}_{3}, \mathrm{BiVO}_{4}, \mathrm{BiOCl}, \mathrm{Bi}_{2} \mathrm{WO}_{6}$ have much attention in field of photocatalysis because of their narrow band gap, chemically and thermally stable and nontoxic [1,2]. Among of them, $\mathrm{BiVO}_{4}$ which is an effective photocatalyst for pollutant photodegradation and water splitting under visible-light irradiation [3] and carbon dioxide reduction has attracted increasing attention $[4,5]$. It is well known that $\mathrm{BiVO}_{4}$ powders have three crystal structure types: monoclinic scheelite (s-m $\left.\mathrm{BiVO}_{4}\right)$, tetragonal zircon (z-t $\left.\mathrm{BiVO}_{4}\right)$ and tetragonal scheelite $\left(\mathrm{s}-\mathrm{t} \mathrm{BiVO}_{4}\right)$ structure [6]. However, only s-m $\mathrm{BiVO}_{4}$ shows the highest visiblelight driven photocatalyst, which can be attributed to its electronic structure and optical properties. It possesses a narrow band gap $(2.4 \mathrm{eV})$ due to the electronic excitation from a valence band by $\mathrm{Bi} 6 \mathrm{~s}$ or a hybrid orbital of $\mathrm{Bi} 6 \mathrm{~s}$ and $\mathrm{O} 2 \mathrm{p}$ to a conduction band of $\mathrm{V} 3 \mathrm{~d}$, allowing to the visible light absorption. However, the poor charge-transport characteristics and the weak surface adsorption properties lead to excessive electron-hole recombination, which limit its overall photocatalytic efficiency.

It is well known that shape, size, specific surface area, crystal structure and morphology of semiconductor photocatalysts play an important factor on their photocatalytic activity [7-9]. Thus, to enhance the photocatalytic activity of these semiconductor materials, their fabrication with controlling the morphology and crystal-facets have recently attracted considerable. For example, monoclinic structured $\mathrm{BiVO}_{4}$ nanosheets with exposed $\{010\}$ facets show a much higher photocatalytic activity than the bulk material for degradation of Rhodamine B under solar irradiation [10]. The monoclinic BiVO4 with a highly exposed (040) facet is assigned to be responsible for the high activity of $\mathrm{O}_{2}$ evolution [11].

In this study, $\mathrm{BiVO}_{4}$ powders were prepared by the solvothermal process using bismuth neodecanoate and ammonium metavanadate solutions as precursors and oleic acid as surfactant in water-ethanol media. $\mathrm{BiVO}_{4}$ powders with different morphologies were selectively synthesized by 
adjusting the $\mathrm{Bi} / \mathrm{V}$ molar ratio and preparation temperature. The properties of the as-synthesized $\mathrm{BiVO}_{4}$ powders were investigated by XRD, FE-SEM, Raman spectroscopy, UV-vis DRS spectroscopy and TA-PL. We have also investigated whether the photocatalytic activity of these materials can bring about the decomposition of Rhodamine $\mathrm{B}(\mathrm{RhB})$ in the presence of visible light.

\section{Experimental}

Bismuth neodecanoate $\left(\mathrm{Bi}\left(\mathrm{OCOC}\left(\mathrm{CH}_{3}\right)_{2}\left(\mathrm{CH}_{2}\right)_{5} \mathrm{CH}_{3}\right)_{3}\right)$, ammonium metavanadate $\left(\mathrm{NH}_{3} \mathrm{VO}_{4}\right.$, 99.996\%), and oleic acid (OA, $90 \%$ ) were purchased from Sigma-Aldrich and were used as received without further purification. Ethanol $(99.98 \%)$ and water were of analytical grade and were purchased from Burdick \& Jackson.

$\mathrm{BiVO}_{4}$ materials with various morphologies were prepared using a solvothermal process. Typically, bismuth neodecanoate $(5 \mathrm{mmol})$ was firstly added into the solution containing $\mathrm{OA}(50 \mathrm{~mL})$ and ethanol $(50 \mathrm{~mL})$ under vigorous stirring for $30 \mathrm{~min}$. The as-obtained solution was named as solution A. A proper amount of $\mathrm{NH}_{3} \mathrm{VO}_{4}(\mathrm{Bi} / \mathrm{V}$ molar ratios are adjusted to 1:1, 2:1, and 1:2 for the synthesis of BVO1, BVO2, and BVO3, respectively) was dissolved into $15 \mathrm{~mL}$ of $3 \mathrm{M} \mathrm{NaOH}$ aqueous solution and the as-obtained solution was named as solution B. Afterwards, solution B was added a drop wise into solution A. The mixture was stirred for $1 \mathrm{~h}$ before being transferred into a telfon-lined stainless steel autoclave and heated at $140{ }^{\circ} \mathrm{C}$ for $12 \mathrm{~h}$. After each the reaction, the obtained suspension was centrifuged at $10000 \mathrm{rpm}$ for $10 \mathrm{~min}$. The obtained solids were washed with water and ethanol for several times and dried at $60{ }^{\circ} \mathrm{C}$ overnight, and followed by calcining at $300{ }^{\circ} \mathrm{C}$ for $3 \mathrm{~h}$. We conducted experiments with temperature selected at 100 and $180{ }^{\circ} \mathrm{C}$ in order to examine the effect of synthesis temperature on the morphology of $\mathrm{BiVO}_{4}$ prepared with $\mathrm{Bi} / \mathrm{V}$ molar ratio=2/1. The as-prepared products were denoted as BVO4 and BVO5, respectively. 
The crystal structures of $\mathrm{BiVO}_{4}$ samples were examined by powder X-ray diffraction (XRD) patterns with $\mathrm{Cu} \mathrm{K \alpha}$ radiation $(\lambda=1.5405 \AA)$ in the $2 \theta$ range of $5-30^{\circ}$ at a scan rate of $1.0 \% \mathrm{~min}$ (Rigaku Co. Model DMax). Raman spectra were recorded with Micro Raman spectrometer (Dongwoo Optron, MonoRa500i) in the range 200 to $1000 \mathrm{~cm}^{-1}$ with a laser beam of $785 \mathrm{~nm}$. The morphology of the products was observed by scanning electron microscope (SEM, JEOL JSM6700F), which was operating at an accelerating voltage of $3 \mathrm{kV}$ and equipped with an energy dispersive X-ray spectroscopy (EDS). The UV-vis diffuse reflectance spectrum (UV-vis DRS) of the products were recorded on a Varian Cary 100 using polytetrafluoroethylene (PTFE) as a standard. The indirect band gap energy $\left(\mathrm{E}_{\mathrm{g}}\right)$ of all samples was calculated from the tangent line in the plots of the modified Kubelka-Munk function $\left[\mathrm{F}\left(\mathrm{R}_{\infty}^{\prime}\right) \mathrm{h} \vartheta\right]^{1 / 2}$ versus photon energy.

The formation of hydroxyl radicals $(\cdot \mathrm{OH})$ on the surface of photoirradiated BiVO4 sample is detected by photoluminescence (PL) technique using terephthalic acid as a probe molecule. Terephthalic acid readily reacts with $\mathrm{OH}$ radical generated from the visible illuminated catalyst surfaces to produce 2-hydroxyterephthalic acid (HTA) with a strong fluorescence characteristic peak. The PL peak intensity of HTA is in proportion to the amount of $\mathrm{OH}$ radicals produced in water $[12,13]$. The typical procedure was similar to those used for the photocatalytic decomposition of $\mathrm{RhB}$, as shown above. A base aqueous solution $\left(100 \mathrm{~mL}, \mathrm{TA}=5 \times 10^{-4} \mathrm{M}\right.$, and $\left.\mathrm{NaOH}=2 \times 10^{-3} \mathrm{M}\right)$ was added to the reactor instead of RhB. After $1 \mathrm{~h}$ illuminated, $3 \mathrm{~mL}$ of the suspension was withdrawn and filtered through a $0.22 \mu \mathrm{m}$ membrane filter to get the clear solution. Fluorescence spectra were recorded on a Hitachi F-4500 fluorescence spectrophotometer (FL) using the $315 \mathrm{~nm}$ excitation light.

We calculated the photocatalytic activities of samples after performing photocatalytic decomposition of RhB under visible light using a 300W Xe-arc lamp (Oriel) and a $410 \mathrm{~nm}$ cut-off filter. The light was passed through a $10 \mathrm{~cm}$ thick IR water filter, and then it was focused onto a 150 $\mathrm{mL}$ Pyrex using a quartz window. The $\mathrm{pH}$ value of the solution was maintained at 7.0; the temperature of the solution was maintained within a range of $23-25^{\circ} \mathrm{C}$. To determine the catalytic 
activity in these experiments, the reactor was filled with a mixture of $\mathrm{RhB}$ aqueous solution $\left(10^{-5} \mathrm{M}\right.$, $100 \mathrm{~mL}$ ) and the given photocatalyst $(100 \mathrm{mg})$. Before irradiation, the mixture was magnetically stirred in dark conditions for 60 minutes. Thus, we ensured an adsorption-desorption equilibrium between the surface of the photocatalyst and the organic molecules. At regular time intervals, we withdrew $3 \mathrm{~mL}$ of the suspension and filtered it through a $0.22 \mu \mathrm{m}$ membrane filter to produce a clear solution. A decrease in the concentration of $\mathrm{RhB}$ solution was determined with a UV-visible spectrophotometer (Mecasys Optizen Pop) at $\lambda=554 \mathrm{~nm}$.

\section{Results and discussion}

\subsection{Characterization of $\mathrm{BiVO}_{4}$ samples}

Fig. 1 shows the XRD patterns of $\mathrm{BiVO}_{4}$ samples, which were prepared using different $\mathrm{Bi} / \mathrm{V}$ molar ratio(A) and different synthesis temperature(B). When $\mathrm{BiVO}_{4}$ were prepared at the $\mathrm{Bi} / \mathrm{V}$ molar ratio $=1 / 1(\mathrm{BVO})$ and 2/1 $(\mathrm{BVO} 2)$, all the XRD peaks indexed well with the monoclinic phase of $\mathrm{BiVO}_{4}$ (JCPDS 14-00688); the peaks appeared at $2 \theta=29^{\circ}$, while the splitting of peaks occurred at $18.5^{\circ}, 35^{\circ}$, and $46^{\circ}$, respectively, corresponding with the patterns reported earlier [14]. No peaks of any other phases or impurities were detected. When $\mathrm{BiVO}_{4}$ were prepared at the $\mathrm{Bi} / \mathrm{V}$ molar ratio= 1/2 (BVO3), however, the XRD peaks exhibited similar patterns to that of s-m $\mathrm{BiVO}_{4}$ and showed coexistence of $\mathrm{NaV}_{6} \mathrm{O}_{15}$ (JCPDS 24-1155) phase. 

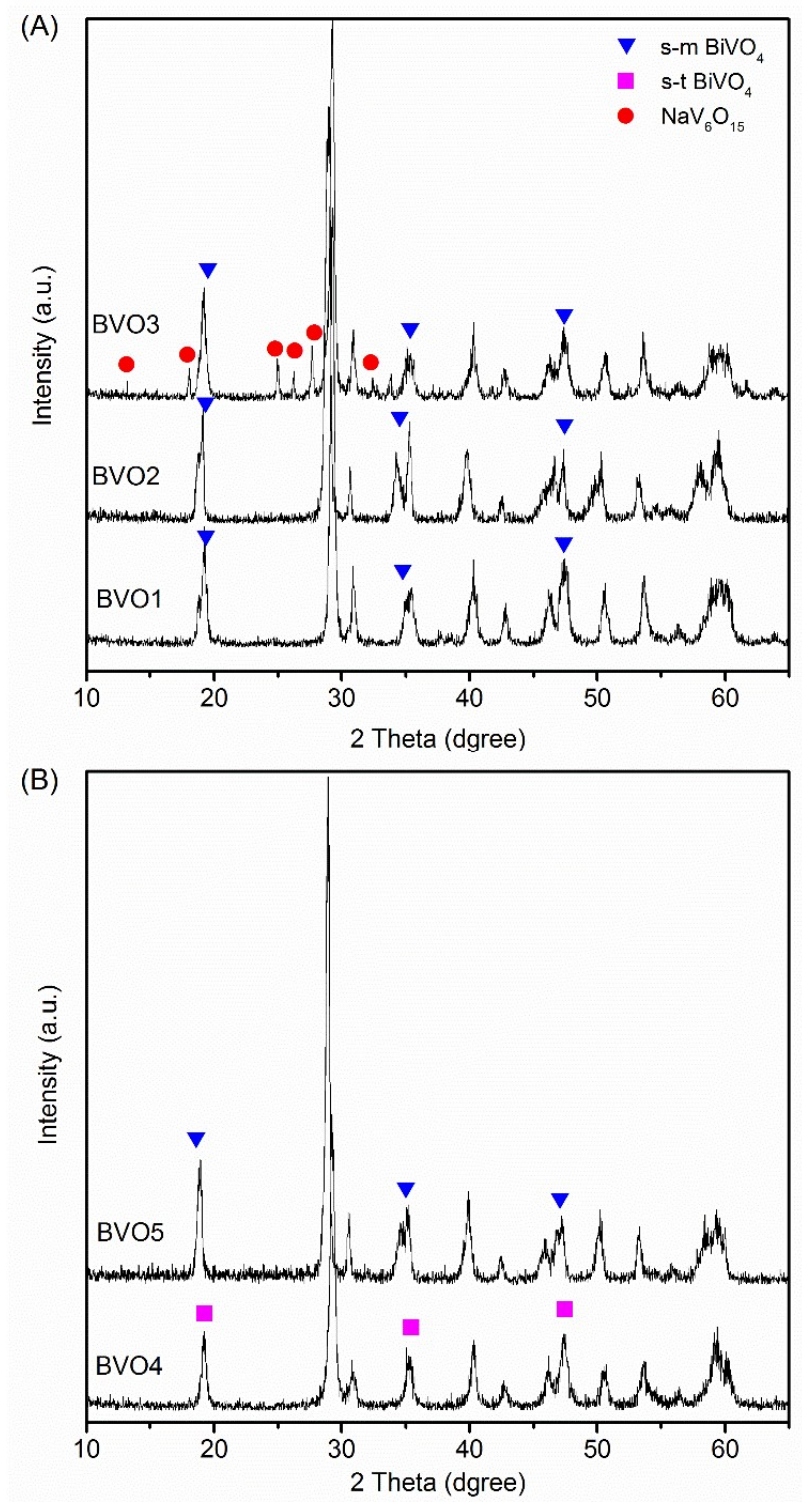

Fig. 1. XRD patterns of $\mathrm{BiVO}_{4}$ samples prepared using different $\mathrm{Bi} / \mathrm{V}$ molar ratio (A) and different synthesis temperature $(\mathrm{B})$.

When $\mathrm{BiVO}_{4}$ samples were prepared using different synthesis temperature, the XRD peaks showed the different patterns (Fig. 1B). When $\mathrm{BiVO}_{4}$ samples were prepared at $100{ }^{\circ} \mathrm{C}(\mathrm{BVO} 4)$, the XRD peaks indexed well with the tetragonal phase of $\mathrm{BiVO}_{4}$ (JCPDS 14-00133) and no monoclinic phase of $\mathrm{BiVO}_{4}$. However, all the XRD peaks indexed well with the monoclinic phase of $\mathrm{BiVO}_{4}$ with an increase of synthesis temperature up to 140 and $180^{\circ} \mathrm{C}$. This result indicated that the monoclinic phase of $\mathrm{BiVO}_{4}$ samples could be obtained more than $140^{\circ} \mathrm{C}$ of solvothermal synthesis temperature. 
Fig. 2 shows the Raman spectra of $\mathrm{BiVO}_{4}$ samples, which were prepared using different $\mathrm{Bi} / \mathrm{V}$ molar ratio(A) and different synthesis temperature(B). According to group theory, the monoclinic phase of $\mathrm{BiVO}_{4}$ materials have six Raman-active modes: the external mode of $\mathrm{BiVO}_{4}\left(210 \mathrm{~cm}^{-1}\right)$, the asymmetric deformation mode of $\mathrm{VO}_{4}{ }^{3-}\left(324 \mathrm{~cm}^{-1}\right)$, the symmetric deformation mode of $\mathrm{VO}_{4}{ }^{3-}(366$ $\left.\mathrm{cm}^{-1}\right)$, the asymmetric stretching mode of V-O bonds $\left(640\right.$ and $\left.710 \mathrm{~cm}^{-1}\right)$ and the symmetric stretching mode of V-O bonds $\left(830 \mathrm{~cm}^{-1}\right)[7,15]$. As shown in Fig. 2(A), BVO1 and BVO2 samples exhibited all Raman signals corresponding to monoclinic phase. Furthermore, no Raman signals corresponding to bismuth oxides or vanadium oxides was observed in these samples, which is consistent with the results of XRD patterns. For BVO3 sample, however, the peak appeared at 506 $\mathrm{cm}^{-1}$ was attributed to $\mathrm{NaV}_{6} \mathrm{O}_{15}$ phase due to the excess of $\mathrm{V}$ content. In addition, the $\mathrm{V}-\mathrm{O}$ bond length can be calculated using the empirical expression: $v\left[\mathrm{~cm}^{-1}\right]=21,349 * \exp (-1.9176 \mathrm{R}[\AA])[16]$, wherein $v$ and $R$ are the Raman shift and the bond length, respectively. The transition of the $v_{s}(V-O)$ band shift of BVO1, BVO2 and BVO3 sample are $835.47,833.98$ and $835.47 \mathrm{~cm}^{-1}$, respectively. The $\mathrm{V}-\mathrm{O}$ bond lengths in BVO1, BVO2 and BVO3 were calculated to have 1.690, 1.692 and $1.69 \AA$, respectively.

As shown in Fig. 2(B), we can observe the transition of the $v_{\mathrm{s}}(\mathrm{V}-\mathrm{O})$ band shift of BVO4 and BVO5 samples at $833.98,818.05$ and $830.49 \mathrm{~cm}^{-1}$, respectively. In addition, the V-O bond lengths in BVO4 and BVO5 were obtained to have 1.700 and $1.691 \AA$. This result indicates that the BVO4 sample has a tetragonal scheelite phase, while BVO2 and BVO5 samples show to have a monoclinic scheelite phase owing to that the band corresponding to symmetric $\mathrm{V}-\mathrm{O}$ stretching mode in $\mathrm{m}-\mathrm{s}$ $\mathrm{BiVO}_{4}(\mathrm{BVO} 2$ and BVO5) shifts toward higher wavenumber (the $\mathrm{V}-\mathrm{O}$ bond length decreases) compared to s-t $\mathrm{BiVO}_{4}$ (BVO4). From the XRD data and Raman spectra, the monoclinic scheelite phase $\mathrm{BiVO}_{4}$ sample can be obtained at higher solvothermal synthesis temperature more than $140{ }^{\circ} \mathrm{C}$. 

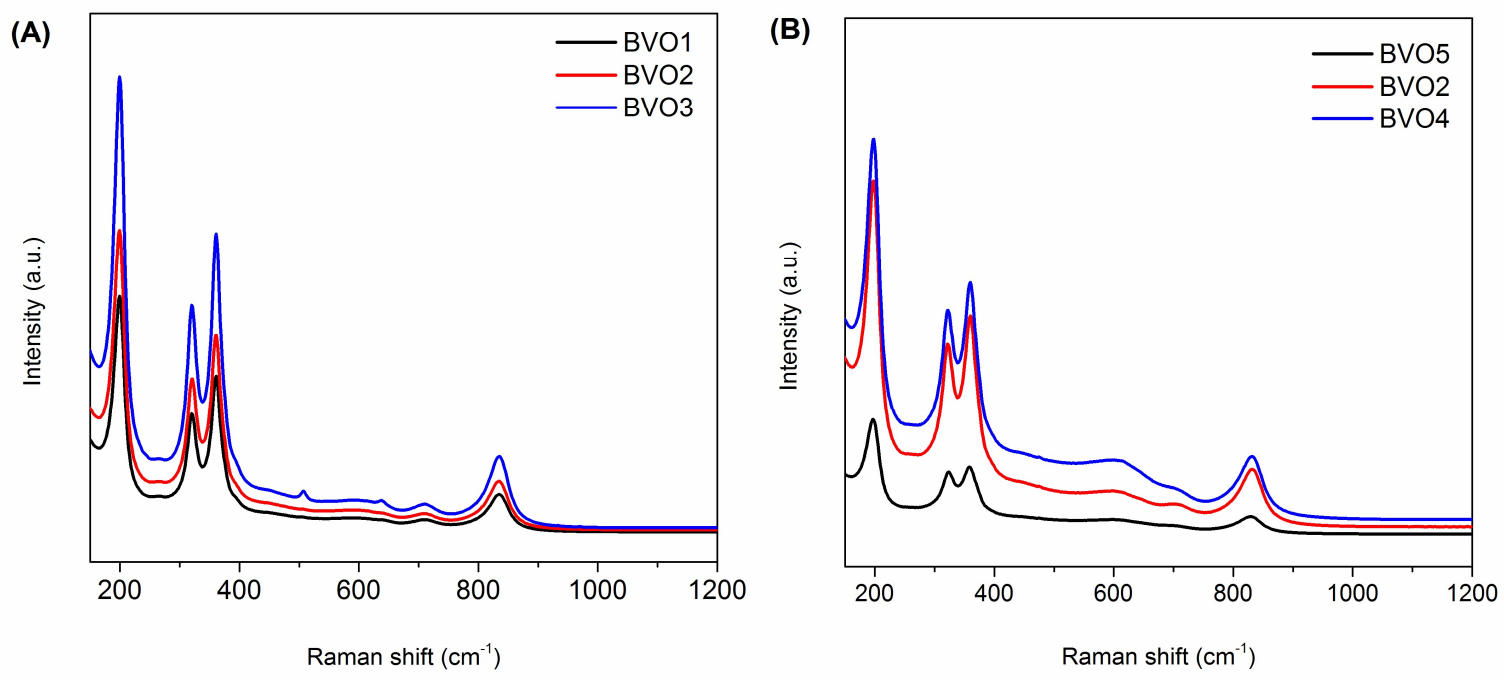

Fig. 2. Raman spectra of $\mathrm{BiVO}_{4}$ samples prepared using different $\mathrm{Bi} / \mathrm{V}$ molar ratio (A) and different synthesis temperature (B).

Fig. 3 shows the SEM images of $\mathrm{BiVO}_{4}$ samples, which were prepared using different $\mathrm{Bi} / \mathrm{V}$ molar ratio and different synthesis temperature. As shown in Fig. 3, the morphologies and shapes of $\mathrm{BiVO}_{4}$ samples varied according to the $\mathrm{Bi} / \mathrm{V}$ molar ratio and synthesis temperature. This result was conceded that the morphology of $\mathrm{BiVO}_{4}$ is dependent on the preparation conditions.

When $\mathrm{BiVO}_{4}$ sample was prepared at the $\mathrm{Bi} / \mathrm{V}$ molar ratio= $1 / 1(\mathrm{BVO})$, the product exhibited ellipsoidal shape morphology with a diameter of about $0.53 \pm 0.09 \mu \mathrm{m}$. The $\mathrm{BiVO}_{4}$ sample was prepared in the excess bismuth (BVO2) led to the formation of needle-like morphology with $1.52 \pm$ $0.15 \mu \mathrm{m}$ in length. When the $\mathrm{BiVO}_{4}$ sample was prepared in the excess vanadium (BVO3), however, the mixture of spherical and rods shape was observed (Fig. 3(C)).

As shown in Fig. 3(D) and (E), the synthesis temperature also played an important role on the morphologies of $\mathrm{BiVO}_{4}$ samples. When $\mathrm{BiVO}_{4}$ sample was prepared at lower temperature (BVO4), non-uniform needle-like morphology of $\mathrm{BiVO}_{4}$ was observed. In addition, when $\mathrm{BiVO}_{4}$ sample was prepared at $180{ }^{\circ} \mathrm{C}(\mathrm{BVO5}), \mathrm{BiVO}_{4}$ sample with a mixture of ellipsoidal and rod morphology was obtained. This result suggests that the preparation conditions such as, the $\mathrm{Bi} / \mathrm{V}$ molar ratio and synthesis temperature, have significantly effects on the morphologies of the $\mathrm{BiVO}_{4}$ samples. 

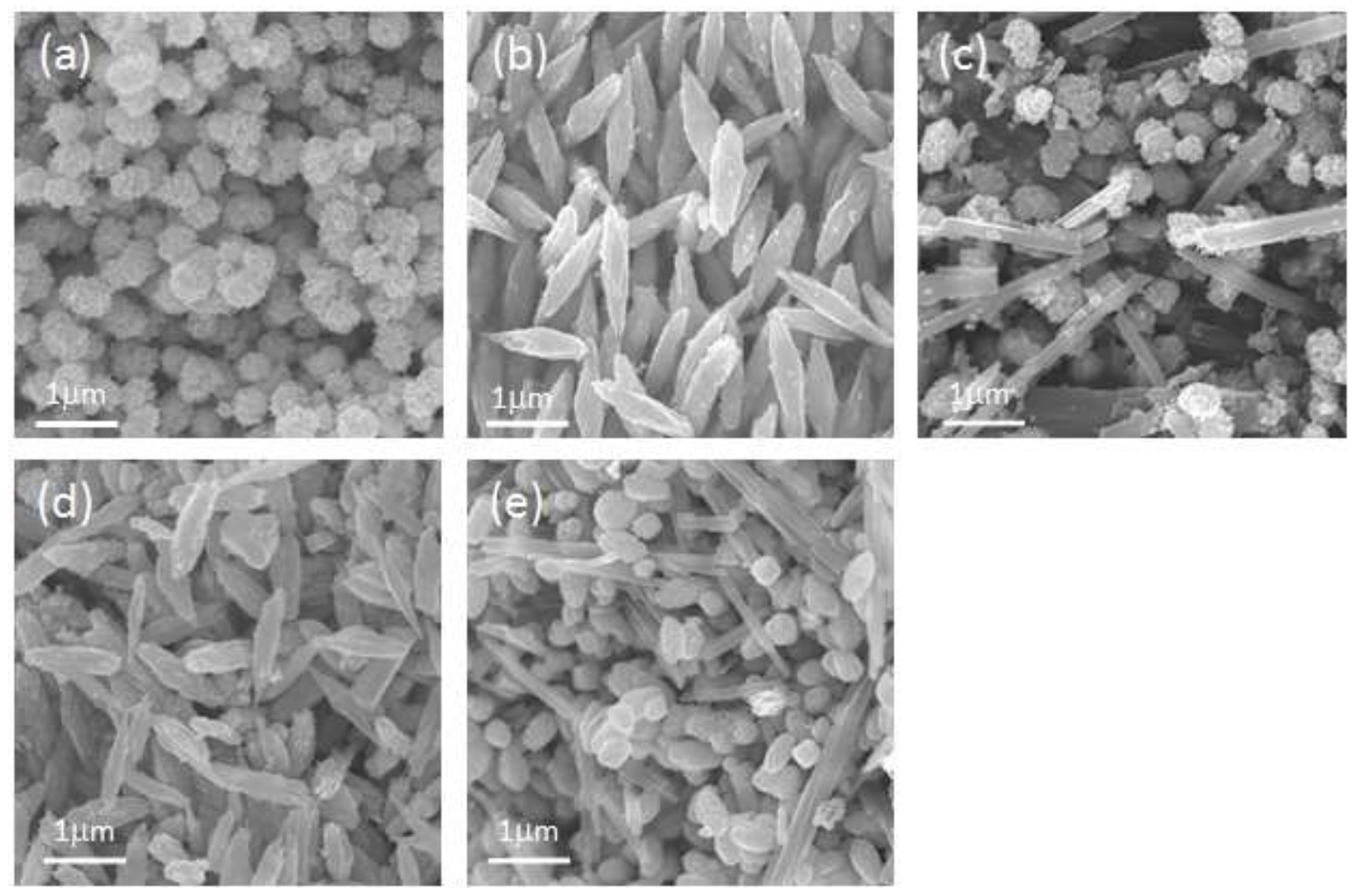

Fig. 3. SEM images of $\mathrm{BiVO}_{4}$ samples prepared using different $\mathrm{Bi} / \mathrm{V}$ molar ratio and different synthesis temperature: a) BVO1, b) BVO2, c) BVO3, d) BVO4 and e) BVO5.

The light absorption properties of photocatalysts were examined in DRS. Fig. 4 shows the DRS spectra of as-prepared $\mathrm{BiVO}_{4}$ samples, which were prepared using different $\mathrm{Bi} / \mathrm{V}$ molar ratio(A) and different synthesis temperature(B). As shown in Fig. 4, all the catalysts displayed strong absorption in the visible range of the electromagnetic spectrum. Owing to the absorbance of visible light, the photocatalytic property of $\mathrm{BiVO}_{4}$ materials was enhanced in the visible region of electromagnetic spectrum. The indirect band gap energy $\left(E_{\mathrm{g}}\right)$ of all the samples was calculated from the tangent lines obtained in the plots of modified Kubelka-Munk function $\left[F\left(R_{\infty}^{\prime}\right) h \vartheta\right]^{1 / 2}$ versus photon energy. The band gap values of various $\mathrm{BiVO}_{4}$ samples are presented in Table 1. As shown in Table 1, the estimated band gap values of $\mathrm{BiVO}_{4}$ samples are obtained in the range of $2.34-2.43 \mathrm{eV}$. 

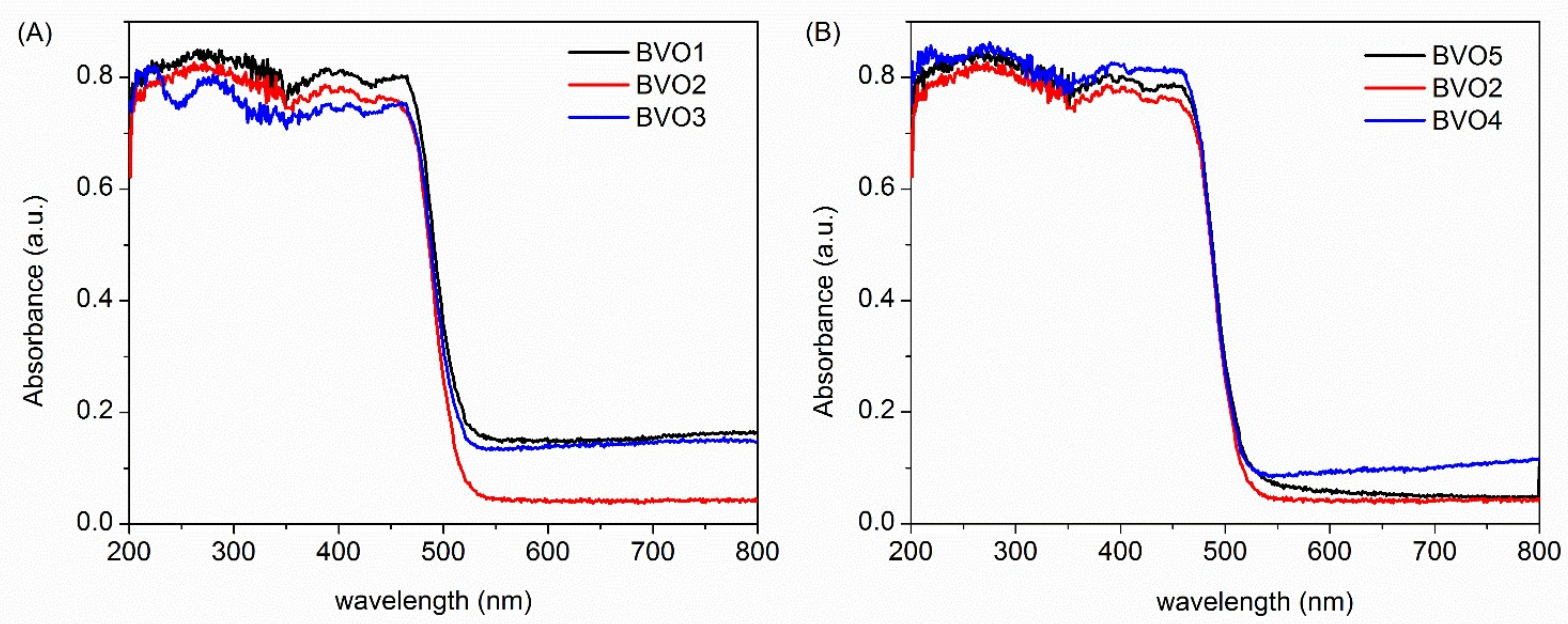

Fig. 4. UV-vis spectra of $\mathrm{BiVO}_{4}$ samples prepared using different $\mathrm{Bi} / \mathrm{V}$ molar ratio (A) and different synthesis temperature (B).

Table 1 . The physical properties and photocatalytic activity of $\mathrm{BiVO}_{4}$ samples.

\begin{tabular}{ccc}
\hline Sample & $E_{\text {band gap }}(\mathrm{eV})$ & $k^{\prime}\left(\times 10^{-3} \mathrm{~min}^{-1}\right)$ \\
\hline BVO1 & 2.37 & 9.0 \\
BVO2 & 2.43 & 42.8 \\
BVO3 & 2.39 & 4.0 \\
BVO4 & 2.36 & 1.0 \\
BVO5 & 2.34 & 30.0 \\
\hline
\end{tabular}

The PL emission spectrum excited at $315 \mathrm{~nm}$ of terephthalic acid solution was measured under visible light irradiation. Fig. 5 shows the changes of PL spectra of terephthalic acid solution with $1 \mathrm{~h}$ visible light irradiation time on the BiVO4 samples prepared using different $\mathrm{Bi} / \mathrm{V}$ molar ratio. As shown in Fig. 5, no photoluminescence signal was observed in the absence of photocatalyst. However, for the BVO1, BVO2 and BVO3 samples, a blue emission signal at approximately $425 \mathrm{~nm}$ was observed. This result suggests that the signal of PL is only caused 2-hydroxyterephthalic acid obtained by the reaction of terephthalic acid with the $\mathrm{OH}$ radical formed on the interface of the photocatalyst/water during visible light irradiation. The PL peak of BVO2 sample shows the highest 
intensity among of all $\mathrm{BiVO}_{4}$ samples. The formation rate of $\mathrm{OH}$ radicals shows a good correlation with the photocatalytic activity.

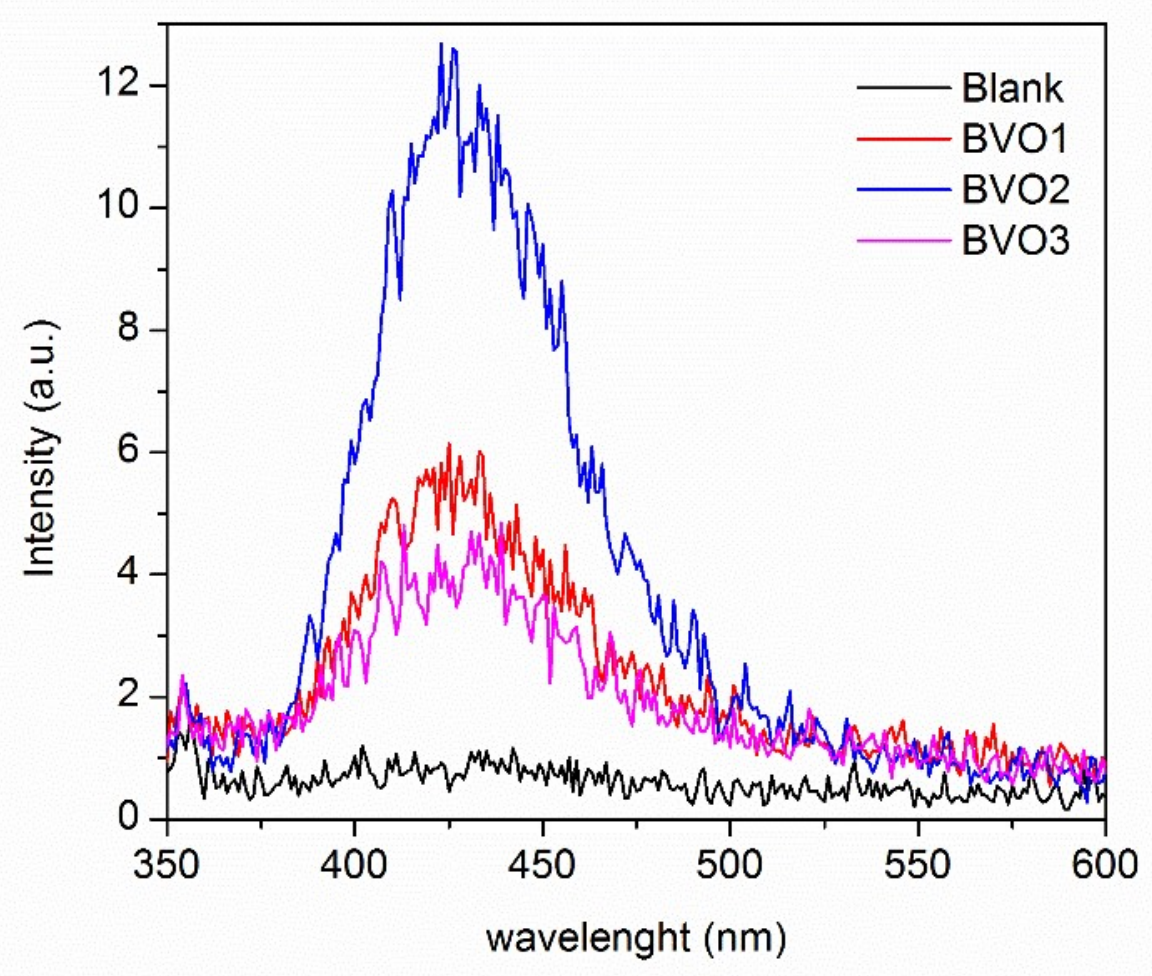

Fig. 5. Fluorescence emission spectra of $\mathrm{BiVO}_{4}$ samples prepared using different $\mathrm{Bi} / \mathrm{V}$ molar ratio in the presence of terephthalic acid.

\subsection{Photocatalytic test}

In order to evaluate the photocatalytic activities of the as-synthesized $\mathrm{BiVO}_{4}$ samples, we investigated the degradation ability of $\mathrm{RhB}$ dye in water in the presence of visible light. Fig. 6 shows the temporal evolution of the UV-vis spectra produced by the photodegradation of RhB dye. In this reaction, $\mathrm{BiVO}_{4}$ sample prepared at $\mathrm{Bi} / \mathrm{V}$ molar ratio=1/1(BVO2) was used as the photocatalyst in the presence of visible light $(\lambda>400 \mathrm{~nm})$. As seen in the above spectra, the absorption of $\mathrm{RhB} / \mathrm{BiVO} 4$ sample and suspensions gradually decreased during the photodegradation process. In addition, the major absorption peak, which corresponds to $\mathrm{RhB}$, was shifted from 554 to $500 \mathrm{~nm}$ in a step-wise manner. Thus, the ethyl groups were removed one by one in this reaction. This finding is in good 
agreement with the previous literature [17].

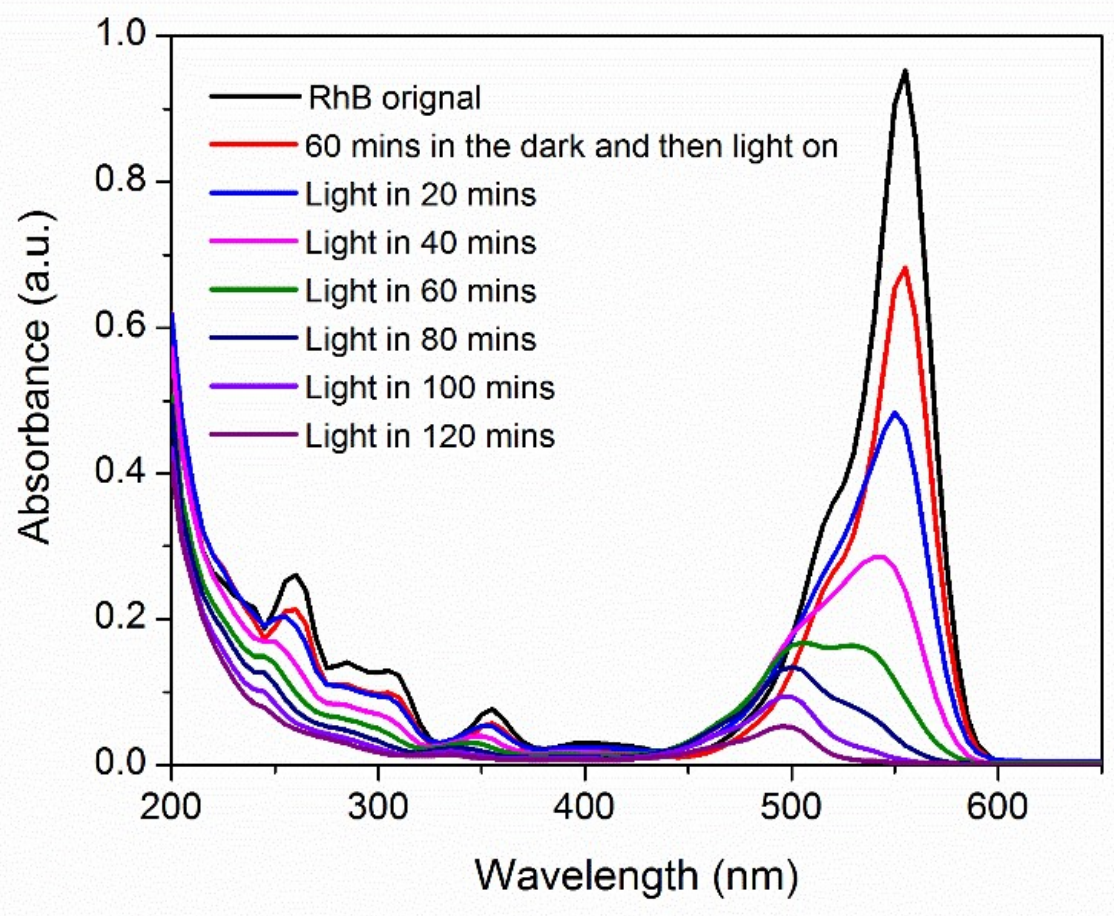

Fig. 6. UV-vis absorption spectra of RhB solution separated from catalyst suspension during illumination using BVO2 sample.

It is a well-known fact that the photocatalytic oxidation of organic pollutants follows LangmuirHinshelwood kinetics [18], where the rate is proportional to the coverage $\theta$ :

$r=-\frac{d c}{d t}=k \theta=k \frac{K C}{1+K C}$

Here, $k$ is the true rate constant; it is dependent upon various parameters, such as the mass of the catalyst, the flux efficiency, and oxygen coverage. $K$ is the adsorption coefficient of the reactant, and $C$ is the concentration of the reactant. When $C$ is very small, the product $K C$ is negligible with respect to unity. Under these conditions, Eq. (1) represents a first-order kinetic reaction. When the parameters of Eq. (1) are set to the initial conditions of a photocatalytic procedure, $t=0$ and the concentration can be given as $C=C_{0}$. Substituting these initial values of reactions in Eq. (1), we obtain Eq. (2) as follows; 
$-\ln \left(\frac{C}{C o}\right)=k_{a p p} t$

where $k_{\text {app }}$ is the apparent first-order reaction constant

In Fig. 7 and Table 1, we have presented how visible light influences the photocatalytic activity associated with the decomposition of $\mathrm{RhB}$ over $\mathrm{BiVO}_{4}$ samples, which were prepared using different $\mathrm{Bi} / \mathrm{V}$ molar ratio(A) and different synthesis temperature(B). When a blank test was carried out in the absence of the photocatalyst, about $7 \%$ of the $\mathrm{RhB}$ was decomposed after $2 \mathrm{~h}$ by the photolysis reaction.

As shown in Fig. 7, $\mathrm{BiVO}_{4}$ sample prepared at $\mathrm{Bi} / \mathrm{V}$ molar ratio=2/1(BVO2) shows the highest photocatalytic activity in the photodegradation of $\mathrm{RhB}$ under visible light irradiation. The $\mathrm{k}$ value of BVO2 catalyst was $42.8 \times 10^{-3} \mathrm{~min}^{-1}$, which is much higher than that of $\mathrm{BiVO}_{4}$ samples prepared different $\mathrm{Bi} / \mathrm{V}$ molar ratio. However, BVO4 sample shows the lowest photocatalytic activity, even though it was prepared with the same Bi/V molar ratio and similar morphology with BVO2 sample. It is thought that BVO4 sample possesses the tetragonal scheelite phase, which is known to have low photocatalytic activity on the decomposition of organic dyes.
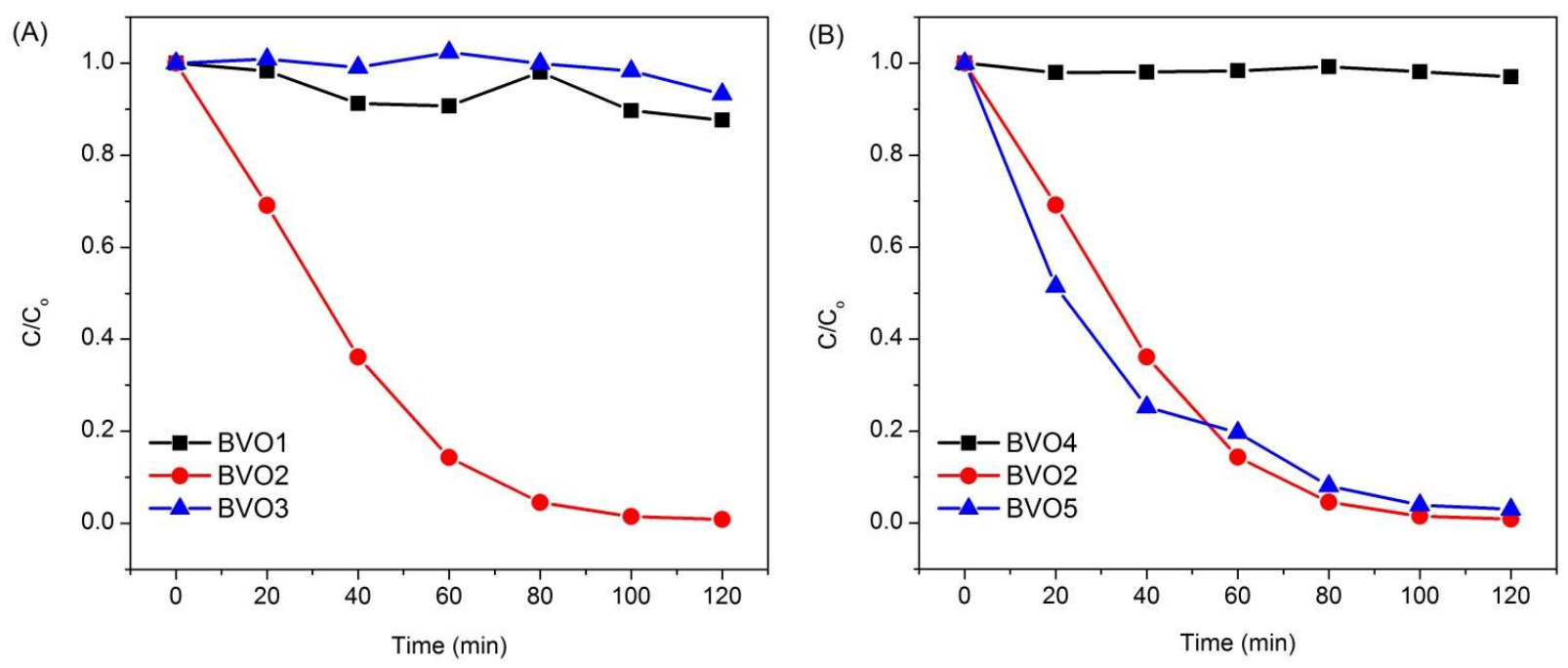

Fig. 7. Photocatalytic decomposition of $\mathrm{RhB}$ over $\mathrm{BiVO}_{4}$ samples prepared using different $\mathrm{Bi} / \mathrm{V}$ molar ratio (A) and different synthesis temperature (B). 
It is well known that $\mathrm{OH}$ radical plays an important role on the photocatalytic decomposition of organic dyes [13]. Generally, the greater the formation rate of $\mathrm{OH}$ radicals is, the higher separation efficiency of electron-hole pairs is achieved. Therefore, the photocatalytic activity is in positive correlation to the formation rate of $\mathrm{OH}$ radicals, namely, a faster formation rate of $\mathrm{OH}$ radicals leads to a higher photocatalytic activity. As shown in Fig. 5, BVO2 sample shows the highest PL peak, which has the highest formation rate of $\mathrm{OH}$ radicals and the highest photocatalytic activity. This result suggests that the formation rate of $\mathrm{OH}$ radicals shows a good correlation with the photocatalytic activity.

\section{Conclusion}

A highly crystallized monoclinic-scheelite type $\mathrm{BiVO}_{4}$ powders were successfully synthesized by solvothermal method from bismuth neodecanoate and ammonium metavanadate solutions in water-ethanol media, combined with the introduction of oleic acid as surfactant. The physical properties of the synthesized $\mathrm{BiVO}_{4}$ powders were investigated by XRD, FE-SEM, Raman spectroscopy, UV-vis DRS spectroscopy and TA-PL. From the XRD data and Raman spectra, the monoclinic scheelite phase $\mathrm{BiVO}_{4}$ sample can be obtained at higher solvothermal synthesis temperature more than $140^{\circ} \mathrm{C}$. The preparation conditions such as, the $\mathrm{Bi} / \mathrm{V}$ molar ratio and synthesis temperature, have significantly effects on the morphologies of the $\mathrm{BiVO}_{4}$ samples. $\mathrm{BVO} 2$ sample shows the highest PL peak, which has the highest formation rate of $\mathrm{OH}$ radicals and the highest photocatalytic activity. This result suggests that the formation rate of $\mathrm{OH}$ radicals shows a good correlation with the photocatalytic activity.

\section{References}

1. Ye, L.; Su, Y.; Jin, X.; Xie, H; Zhang, C. Recent advances in BiOX $(\mathrm{X}=\mathrm{Cl}, \mathrm{Br}$ and I) photocatalysts: synthesis, modification, facet effects and mechanisms. Environ. Sci. Nano 2014, 1, 90-112. 
2. Sun, S; Wang, W. Advanced chemical compositions and nanoarchitectures of bismuth based complex oxides for solar photocatalytic application. $R S C A d v$. 2014, 4, 47136-47152.

3. Park, Y.; McDonald, K.J.; Choi, K.-S. Progress in bismuth vanadate photoanodes for use in solar water oxidation. Chem. Soc. Rev. 2013, 2321-2337.

4. Liu, Y.; Huang, B.; Dai, Y.; Zhang, X.; Qin, X.; Jiang, M.; Whangbo M. H. Selective ethanol formation from photocatalytic reduction of carbon dioxide in water with BiVO4 photocatalyst. Catal. Commun. 2009,11, 210-213.

5. Mao, J.; Peng, T.; Zhang, X.; Li, K.; Zan, L. Selective methanol production from photocatalytic reduction of $\mathrm{CO}_{2}$ on $\mathrm{BiVO}_{4}$ under visible light irradiation. Catal. Commun. 2012 , 28, 38-41.

6. Lim, A.R.; Choh, S.H.; Jang, M.S. Prominent ferroelastic domain walls in $\mathrm{BiVO}_{4}$ crystal. $J$. Physics-Condensed Matter. 1995, 7, 7309-7323.

7. Yu, J.; Kudo, A. Effects of structural variation on the photocatalytic performance of hydrothermally synthesized BiVO 4 . Adv. Funct. Mater. 2006, 16, 2163-2169.

8. Yang, T.; Xia, D.; Chen, G.; Chen, Y. Influence of the surfactant and temperature on the morphology and physico-chemical properties of hydrothermally synthesized composite oxide $\mathrm{BiVO}_{4}$. Mater. Chem. Phys. 2009, 114, 69-72.

9. Obregon, S.; Caballero, A.; Colon, G. Hydrothermal synthesis of BiVO 4 : Structural and morphological influence on the photocatalytic activity. Appl. Catal. B-Environmental 2012, 112, 5966.

10. Xi, G.; Ye, J. Synthesis of bismuth vanadate nanoplates with exposed $\{001\}$ facets and enhanced visible-light photocatalytic properties. Chem. Commun. 2010, 46, 1893-1895

11. Wang, D.; Jiang, H.; Zong, X.; Xu, Q.; Ma, Y.; Li, G.; Li, C. Crystal facet dependence of water oxidation on $\mathrm{BiVO}_{4}$ sheets under visible light irradiation. Chem. - A Eur. J. 2011, 17, 1275-1282.

12. Yu, J.; Wang, W.; Cheng, B.; Su, B.L. Enhancement of photocatalytic activity of mesporous $\mathrm{TiO}_{2}$ powders by hydrothermal surface fluorination treatment. J. Phys. Chem. C 2009, 113, 67436750 .

13. Hu, Y.; Li, D.; Sun, F.; Wang, H.; Weng, Y.; Xiong, W.; Shao, Y. One-pot template-free synthesis of heterophase $\mathrm{BiVO}_{4}$ microspheres with enhanced photocatalytic activity. RSC Adv. 2015, 5, 54882-54889.

14. Tokunaga, S.; Kato, H.; Kudo, A. Selective preparation of monoclinic and tetragonal $\mathrm{BiVO}_{4}$ with scheelite structure and their photocatalytic properties. Chem. Mater. 2001, 13, 4624-4628.

15. Frost, R.L.; Henry, D.A.; Weier, M.L.; Martens, W. Raman spectroscopy of three polymorphs of $\mathrm{BiVO}_{4}$ : clinobisvanite, dreyerite and pucherite, with comparisons to $\left(\mathrm{VO}_{4}\right)^{3}$-bearing minerals: 
namibite, pottsite and schumacherite. J. Raman Spectrosc. 2006, 37, 722-732.

16. Brown, I.D.; Wu, K.K. Empirical parameters for calculating cation-oxygen bond valences. Acta Crystallogr. Sect. B Struct. Crystallogr. Cryst. Chem. 1976, 32, 1957-1959.

17. Nguyen, D.T.; Hong, S.S. Synthesis of $\mathrm{BiVO}_{4}$ nanoparticles using microwave process and their photocatalytic activity under visible light irradiation, J. Nanosci. Nanotech. 2017, 17, 2690-2694.

18. Jung, W.Y.; Hong, S.S. Photocatalytic decomposition of methylene blue over yttrium ion doped Ti-SBA-15 catalysts Catal. Today, 2011, 164, 395-398. 